\title{
Construção de tecnologias educativas como forma de educação em saúde para a prevenção da Covid-19: relato de experiência
}

\author{
Construction of educational technologies as a form of health education for the prevention \\ of Covid-19: experience report
}

Construcción de tecnologías educativas como una forma de educación sanitaria para la prevención de Covid-19: informe de experiencia

José Benedito dos Santos Batista Neto ${ }^{1 *}$, Thiago Marcírio Gonçalves de Castro ${ }^{1}$, Renata Campos de Sousa Borges ${ }^{1}$, Daniele Lima dos Anjos Reis ${ }^{1}$, Tania de Sousa Pinheiro Medeiros ${ }^{1}$, Milena Coelho Fernandes Caldato ${ }^{2}$, Nadja da Fonseca Veloso², Renato da Costa Teixeira ${ }^{2}$, José Ronaldo Teixeira de Sousa Júnior ${ }^{3}$, Ismaelino Mauro Nunes Magno ${ }^{3}$.

\section{RESUMO}

Objetivo: Relatar a construção de duas tecnologias educacionais com o tema de "Orientações para a limpeza terminal de transportes coletivos e individuais e uso de Equipamentos de Proteção Individual (EPI) necessário ao trabalhador de limpeza para a prevenção da Covid-19" como forma de combate a pandemia. Relato de Experiência: $O$ presente trabalho trata-se de um estudo descritivo, do tipo relato de experiência, especificamente, sobre a criação de um vídeo e de uma cartilha informativa como forma de combate a covid19, sendo que tal experiência aconteceu em seis etapas: pesquisa bibliográfica, escolha do tipo de tecnologia, linguagens e recursos gráficos adequados ao público alvo, elaboração da cartilha, elaboração do vídeo e publicação das mídias em aplicativos e redes sociais. Após a divulgação das mídias, foi possível perceber que as mesmas foram bem recebidas pela população. Considerações Finais: Concluiu-se que as tecnologias educacionais virtuais elaboradas são de suma importância para o combate da pandemia de covid19, uma vez que ações de educação em saúde comunitárias não são eficientes em virtude da fácil contaminação do vírus e necessidade de redução de aglomerações.

Palavras-chave: Tecnologia educacional, Educação em saúde, Coronavírus, Enfermagem.

\begin{abstract}
Objective: To report the construction of two educational technologies with the theme of "Guidelines for the terminal cleaning of collective and individual transport and the use of Personal Protective Equipment (PPE) necessary for cleaning workers to prevent Covid-19" as a way of fights the pandemic. Experience report: The present work is a descriptive study, of the experience report type, specifically, about the creation of a video and an information booklet as a way to fight covid-19, and this experience happened in six stages: bibliographic research, choice of technology type, languages and graphic resources appropriate to the target audience, preparation of the booklet, preparation of the video and publication of the media in applications and social networks. After the dissemination of the media, it was possible to realize that they were well received by the population. Final Considerations: It was concluded that the virtual educational technologies developed are of paramount importance for combating the covid-19 pandemic, since community health education actions are not efficient due to the easy contamination of the virus and the need to reduce agglomerations.
\end{abstract}

Keywords: Educational technology, Health education, Coronavirus, Nursing.

\footnotetext{
1 Universidade do Estado do Pará (UEPA), Tucuruí - PA. *E-mail: netto1443@gmail.com

2 Universidade do Estado do Pará (UEPA), Belém - PA.

${ }^{3}$ Centro Universitário do Estado do Pará (CESUPA), Belém - PA.
} 


\section{RESUMEN}

Objetivo: Informar sobre la construcción de dos tecnologías educativas con el tema de "Directrices para la limpieza de terminales de transporte colectivo e individual y el uso de equipos de protección personal (EPP) necesarios para que los trabajadores de limpieza eviten Covid-19" como una forma combate la pandemia. Informe de experiencia: el presente trabajo es un estudio descriptivo, del tipo de informe de experiencia, específicamente, sobre la creación de un video y un folleto informativo como una forma de combatir covid-19, y esta experiencia ocurrió en seis etapas: investigación bibliográfica, elección del tipo de tecnología, idiomas y recursos gráficos adecuados para el público objetivo, preparación del folleto, preparación del video y publicación de los medios en aplicaciones y redes sociales. Después de la difusión de los medios, fue posible darse cuenta de que fueron bien recibidos por la población. Consideraciones finales: Se concluyó que las tecnologías educativas virtuales desarrolladas son de suma importancia para combatir la pandemia de covid19, ya que las acciones de educación comunitaria en salud no son eficientes debido a la fácil contaminación del virus y la necesidad de reducir aglomeraciones.

Palabras-clave: Tecnología educativa, Educación en salud, Coronavirus, Enfermería.

\section{INTRODUÇÃO}

Em dezembro de 2019, um novo tipo de coronavírus foi descoberto em Wuhan, China. Tratava-se do coronavírus 2 da Síndrome Respiratória Aguda Grave (SARS-CoV-2), caracterizado pela alta transmissibilidade de pessoa a pessoa por via e contato aéreo, rapidamente iniciou uma epidemia, que infelizmente evoluiu para a atual pandemia causada pela Doença do Coronavírus em 2019 (Covid-19).

A principal característica da Covid-19 é caracterizada por infecção leve do trato respiratório superior com febre, tosse e alterações típicas nos estudos radiográficos; infecção do trato respiratório inferior envolvendo pneumonia não fatal e fatal com síndrome do desconforto respiratório agudo (LIU H, et al., 2020).

Por ser uma doença nova, não há vacinas aprovadas, tornando a prevenção fundamental. Infelizmente, várias características inespecíficas da doença, a infecciosidade mesmo antes do início dos sintomas, transmissão de pessoas assintomáticas, longo período de incubação, tropismo para superfícies mucosas e duração prolongada da doença dificultam sua prevenção.

Assim, a melhor recomendação é o isolamento de casos confirmados ou suspeitos em casa. Os pacientes e profissionais de saúde devem ser solicitados a usar uma máscara cirúrgica simples e praticar etiquetas e higiene da tosse bem como higienização contínua das mãos (SINGHAL T, 2020).

É importante frisar, que além da transmissão por gotículas respiratórias e contato direto com uma superfície contaminada, há a possibilidade de transmissão por aerossóis que, embora até o momento não existam evidências concretas a respeito, não deve ser completamente descartada (BRASIL, 2020).

Logo, sabendo que o vírus possui alta infecciosidade e ainda não possuímos medidas de tratamento eficazmente comprovadas, o correto a se fazer é a prevenção, a qual compreende, além de medidas de higiene, o isolamento social e para as categorias profissionais de diversos trabalhadores deve-se reforçar a correta utilização de equipamentos de proteção individual (EPI) (OPAS, 2020).

Nesse contexto, estudos apontam que embora o vírus possua uma baixa letalidade, cerca de $3,8 \%$ no Brasil, ele apresenta uma infectividade elevada. Tal afirmação se concretiza quando analisamos o cenário atual da pandemia no Brasil, onde a transmissão comunitária foi declarada em 20 de março (BRASIL, 2020) e, desde então, os números de infectados só sobem, chegando a mais de 2,4 milhões em 29 de Julho de 2020 (WHO, 2020). Ademais, de acordo com uma pesquisa de Kampf $\mathrm{G}$ et al. (2020), os coronavírus podem permanecer em superfícies como vidro, metal ou plástico por até 9 dias em temperatura ambiente. 
Assim, sabendo que a doença se espalha pelo contato, tornou-se hábito alertar para a prática de higiene com frequência, que compreende a correta higienização das mãos com utilização de água e sabão e/ou álcool $70 \%$ e a desinfecção adequada, utilizando uma mistura de água sanitária e água corrente, de objetos e superfícies como de veículos. Neste sentido, a eficácia destes produtos saneantes dá-se por possuírem um mecanismo de ação que visa a destruição da camada de gordura e proteína, através da conexão ao envelope lipídico, fazendo o vírus perder seu poder de infecciosidade e, consequentemente, replicação viral (ANVISA, 2012).

Ainda, sabe-se que a utilização de EPI pelos indivíduos é outra forma de prevenção, funcionando como uma barreira contra riscos biológicos. Esses equipamentos devem estar acessíveis aos trabalhadores e certificados pela Anvisa. Dentre os principais destacam-se: gorro, óculos de proteção ou protetor facial, máscara, avental impermeável de mangas compridas e luvas de procedimentos (BRASIL, 2020). E certamente, devem ser usados por todos que lidam diretamente com paciente ou com a limpeza de locais com grande circulação de pessoas, com os trabalhadores de limpeza.

Apesar das massivas orientações dessas medidas, ocasionou-se a disseminação rápida da doença pelo mundo, que está afetando drasticamente nações, dado que esta já levou muitas pessoas ao estado grave, fazendo-as necessitar de respiradores artificiais, colapsando sistemas de saúde, visto a realidade em países desenvolvidos, a exemplo de Itália e Estados Unidos. Para evitar uma crise de maiores proporções, deve-se aproveitar a educação em saúde mesmo que não tenham muitos casos concentrados em uma determinada região, para estimular o interesse pelo cuidado em casa, redes de atendimento a serem procuradas e para esclarecer o objetivo dos procedimentos e cuidados que deverão ser realizados. Com isso, podemos entender a educação em saúde como peça fundamental na prevenção e continuidade da qualidade de vida dos beneficiados por estas ações (STAMM B, et al., 2019; AZEVEDO A, et al., 2019).

Por se tratar de um período em que a circulação e aglomeração de pessoas estão restritas em muitos países, para evitar mais infecções, tem-se pouco material educativo para orientar a população em geral. Nesse contexto, devemos proporcionar a aproximação das tecnologias educativas com a educação em saúde, dado que tal ação é capaz de proporcionar conhecimentos, bem como influenciar nos costumes de uma comunidade. No mais, ressalta-se que estas tecnologias são ferramentas inovadoras capazes de tornar os indivíduos mais críticos. A partir dessas reflexões, devemos sempre analisar a realidade abordada, e desenvolver tecnologias que auxiliem o ensino-aprendizado dos sujeitos, com isso conseguiremos inverter um determinado problema e obter benefícios, estes apenas proporcionados por meio de uma boa educação (SILVEIRA RSO, et al., 2016).

Dessa forma, o estudo propõe relatar a construção de duas tecnologias educacionais em torno do tema "Orientações para a limpeza terminal de transportes coletivos e individuais e uso de Equipamentos de Proteção Individual (EPI) necessário ao trabalhador da limpeza para a prevenção da Covid-19" como forma de combate a pandemia.

\section{RELATO DE EXPERIÊNCIA}

Trata-se de um estudo descritivo, do tipo relato de experiência acerca da construção de duas tecnologias educacionais como forma de combate da disseminação da Covid-19 em seis municípios da região do lago de Tucuruí, no interior do Pará. Estas tecnologias foram formuladas por acadêmicos do 5 e semestre do Curso de Graduação em Enfermagem da Universidade do Estado do Pará, como forma de prática obrigatória do componente curricular "Tecnologias Educacionais em Saúde e Enfermagem".

A elaboração das tecnologias surgiu para atender demandas de temas loco-regionais do departamento de Vigilância em Saúde e Centro de Referência em Saúde do Trabalhador da saúde pública de Tucuruí. Tal estratégia, realizou-se pela mobilização de acadêmicos de enfermagem para produção de mídias a partir da integração entre os departamentos e Instituições de Ensino Superior. Vale ressaltar que todo o processo ocorreu sob supervisão de uma enfermeira-docente e análise da equipe técnica da vigilância em saúde para a veiculação em redes sociais e aplicativos multiplataforma de mensagens instantâneas. 
Com referência aos pontos definidores para desenvolver as tecnologias, destaca-se que durante a atual epidemia, é sabido que ações de higiene e proteção pessoal são fundamentais para evitar a proliferação da Covid-19. Nesse contexto, os assuntos foram escolhidos por existir um déficit de informações a respeito da limpeza dos transportes coletivos e individuais voltados especificamente para a pandemia, assim como do uso correto de EPI por profissionais da limpeza.

Ademais, por serem dois assuntos específicos e de muita relevância no atual cenário de combate ao vírus, foram desenvolvidas estas tecnologias. Após tomar ciência sobre a temática das tecnologias, iniciou-se o processo de construção, o qual compreende seis etapas: pesquisa bibliográfica, escolha do tipo de tecnologia, linguagens e recursos gráficos adequados ao público alvo, elaboração da cartilha, elaboração do vídeo e publicação das mídias em redes sociais.

Com referência aos critérios de seleção dos pontos temáticos abordados, por meio de uma síncrese entre os autores, definiu-se o público-alvo da tecnologia, como os motoristas de transportes coletivos e trabalhadores da limpeza dos veículos. Posteriormente, definiram-se as temáticas chaves para a busca na literatura, representadas por categorias norteadoras que foram: apresentação do conceito da covid-19, tipos de limpeza adequada para veículos de acordo com a legislação vigente, soluções adequadas à limpeza, interrupção da disseminação do vírus, o EPI adequado para a proteção de trabalhadores da limpeza e medidas de higiene pessoal.

À priori, os acadêmicos foram estimulados pela enfermeira-docente a iniciarem uma pesquisa bibliográfica a partir de documentos com peso de evidências científicas dos anos de 2019 e 2020 sobre a temática. Destarte, foram usados como referência, manuais e protocolos elaborados pelo Ministério da Saúde do Brasil e comunidades científicas internacionais reconhecidas pela Organização Mundial da Saúde, o que garantiu que todas as informações expostas nas mídias fossem confiáveis.

A partir do momento que a coleta bibliográfica e o mapeamento das informações para abordar na ferramenta educacional foram realizados, iniciou-se o processo de construção das tecnologias. Primeiramente, foi criada a Cartilha (Figura 1). Como programa para o desenvolvimento do documento foi utilizado o software de computador Microsoft Office Power Point 2019. Foram utilizadas as seguintes dimensões para a criação: largura de seis centímetros e altura de sete centímetros. Ademais, a cartilha possui 15 páginas, que compreendem a capa, páginas de conteúdo e referências, em fonte Anaheim, tamanho nove pontos, em coloração azul celeste.

Figura 1 - Páginas 1, 2 e 3 da Cartilha Informativa.



Fonte: Batista Neto JBS, et al., 2020. 
Para deixar a cartilha com um teor lúdico, todas as informações foram repassadas por meio de diálogos entre personagens fictícios, que receberam o nome de "Equipe Enfer18, juntos contra a Covid-19". Tratando de conteúdo abordado, foram apresentados ao público o conceito de Limpeza Terminal, os cuidados que devem ser tomados com ônibus e carros particulares, o conceito acerca do EPI e quais devem ser utilizados por agentes de limpeza em ambiente de trabalho (Figura 2 e 3).

Figura 2 - Páginas 4, 5 e 7 da Cartilha Informativa

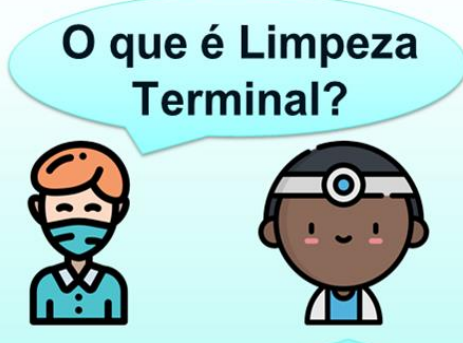

Entende-se por limpeza terminal a higienização completa de áreas como hospitais e até mesmo veículos e, às vezes, a desinfecção para a diminuição da sujidade e redução da população microbiana.

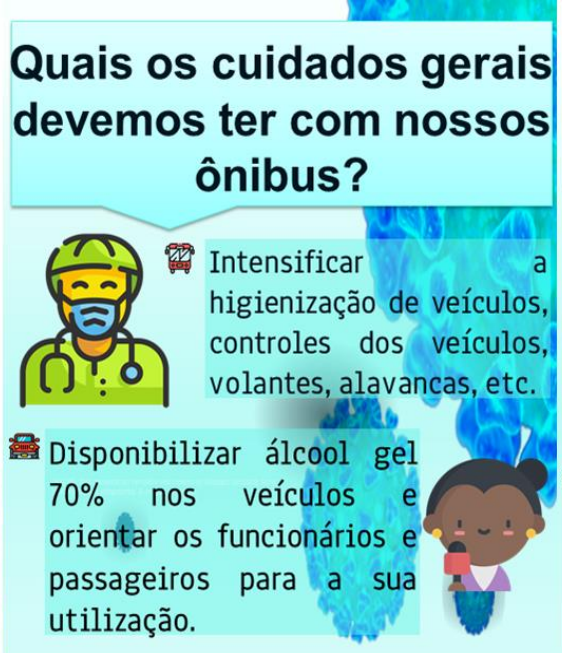

Você ainda quer mais dicas? Então, se liga nessas orientações para o seu quatro rodas.

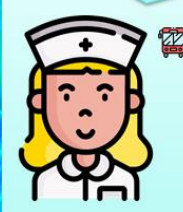

Limpe, constantemente, o painel, volante, alavanca de câmbio e toda superfície plástica com álcool isopropílico $70 \%$, que não danifica 0 material

鯂 Outra dica é esvaziar a lixeira portátil diariamente, principalmente, se houver lenços de papel com secreções de olhos, boca e nariz, que podem conter vírus.

Fonte: Batista Neto JBS, et al., 2020.

Figura 3 - Páginas 10, 12 e 13 da Cartilha Informativa.

\section{Agora, vamos discutir sobre a utilização de EPI pelo trabalhador de limpeza?}

0s Equipamentos de Proteção Individual (EPI), como o próprio nome sugere, são os responsáveis por ajudar na manutenção da saúde e integridade física de pessoas que trabalham em situação de risco. Por isso, o uso de EPI para funcionários da equipe de limpeza e manutenção é importante para protegê-los dos sutis perigos aos quais estão expostos, embora muitas pessoas só associem o uso desse equipamentos à profissionais da saúde.

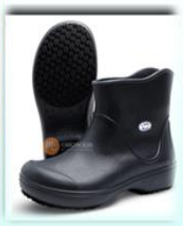
BOTAS ANTIDERRAPANTES: Assim como as luvas, protege contra riscos biológicos, químicos e físicos.

\section{MÁSCARAS, GORROS E} ÓCULOS DE PROTEÇÃO: Fundamentais para a proteção da face e cabelo, ajudando no combate tanto contra 0 vírus, riscos químicos e físicos.

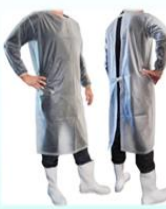
AVENTAIS IMPERMEÁVEIS: Assim com os outros EPI'S é fundamental para a proteção da pele contra os riscos.

Por fim, você, profissional de limpeza não esqueça da sua prevenção e higiene pessoal!

Lave sempre as mãos com água e sabão, ou use álcool em gel $70 \%$.

$\stackrel{1 \mathrm{M} .0}{\leftrightarrow}$ Evite contato direto com outros indivíduos.

Mantenha a calma e siga manuais de saúde oficiais

Fonte: Batista Neto JBS, et al., 2020.

Com a cartilha finalizada, iniciou-se a elaboração do vídeo (Figura 4) por meio da ferramenta de uso online "Powtoon". Tal mídia foi criada obedecendo a definição de imagem de 720p, para que garantisse uma boa visualização. Por conseguinte, o vídeo possui um total de 2 minutos e 56 segundos de duração, o que garantiu que todas as informações fossem passadas no tempo eficaz para quem assiste e lê. Assim como a cartilha, o vídeo aborda a mesma temática (Figuras 4 e 5) e, todas estas informações também foram passadas por meio de falas de personagens fictícios. 
Após a finalização da confecção, as mídias foram encaminhadas para análise da equipe técnica dos departamentos de saúde da rede local e, posteriormente, disseminadas em veículos de comunicação virtuais, enviadas aos grupos de trabalho de profissionais de saúde e população em geral do aplicativo de celular WhatsApp e publicadas em páginas das redes sociais Facebook e Instagram. Tal ação garantiu que tecnologias fossem visualizadas por inúmeras pessoas. Felizmente, foi perceptível a eficiência das ferramentas, uma vez que os indivíduos que as visualizavam faziam um feedback positivo por meio de comentários e ajudavam no compartilhamento para que mais pessoas pudessem apreciar. Como forma de exemplificar os feedbacks, alguns comentários afirmavam que as tecnologias explicavam muito bem e com detalhes os processos de higienização e uso de EPI.

Figura 4 - Momento em que o vídeo traz informações acerca do coronavírus, tempo: 00min33s

\section{Coronavirus}

O coronavírus é uma família de vírus causadores de infecções respiratórias e que provocam a doença chamada COVID-19. Nos casos mais leves, porém, parece um resfriado comum ou uma queixa leve.

Os sintomas mais comuns são:

$\longrightarrow$ Febre

$\rightarrow$ Tosse ou

Dificuldade para respirar.

Entre outros sintomas gripais.

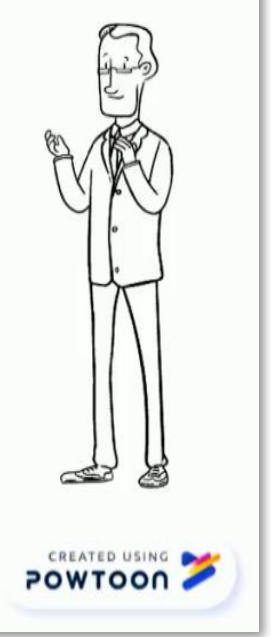

Fonte: Batista Neto JBS, et al., 2020.

Figura 5 - Momento em que o vídeo traz informações acerca da limpeza de veículos, tempo: 01 min13s.

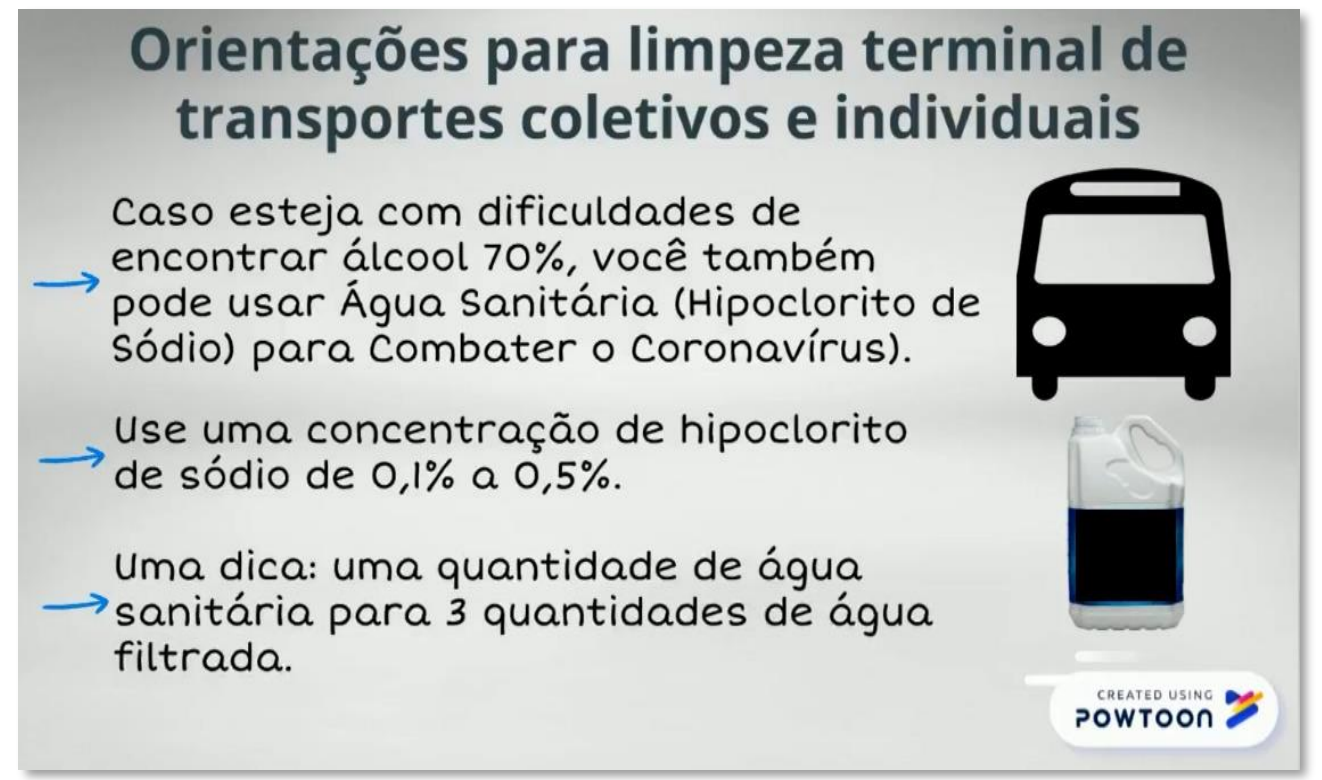

Fonte: Batista Neto JBS, et al., 2020. 


\section{DISCUSSÃO}

A experiência como acadêmicos de Enfermagem frente às pesquisas, criação e apresentação das tecnologias, pôde agregar conhecimentos que contribuíram para melhorar a formação e atuação como futuros enfermeiros frente às diversidades que afetem diretamente a população. Por ser um período em que o contato com o público em geral está limitado, fez-se necessário o uso de tecnologias digitais que pudessem proporcionar orientações corretas e seguras sobre o processo de higienização de ambientes de uso coletivo e proteção pessoal. Para tanto, é necessário que docentes e até mesmo os discentes devam assumir posturas novas e diferenciadas, de modo a promover uma aprendizagem colaborativa, contexto em que as mídias educacionais podem-se apresentar como estratégias didáticas enriquecedoras (SALVADOR PTCO, et al., 2019).

Nesse contexto, a utilização de instrumentos tecnológicos para facilitar a comunicação entre profissional da saúde e a população, deve estar inserida em todo o processo de combate a este vírus causador da Covid19, pois, irá repercutir na qualidade do atendimento, garantia do direito à saúde ao indivíduo, na aquisição de habilidades e confiança, facilitar o reconhecimento dos sintomas, o conhecimento dos fatores desencadeantes e de como evitá-los. Assim, a elaboração de tecnologias é primordial para mediar essa relação, ocasionando em diversos benefícios tanto para o profissional e paciente (BARRETO AEPM e SILVA FRA, 2015; RAMOS TS e ALMEIDA MAPT, 2017).

No setor da saúde, é comum a utilização de tecnologias, compreendidas em uma concepção de produto e processo. Dessa forma, as tecnologias em saúde podem ser divididas em leve, que é o estabelecimento de relações para realização do cuidado (vínculo, gestão de serviços e acolhimento); leve-dura, sendo a construção do conhecimento por meio de conhecimento estruturado (teorias, modelos de cuidado, cuidado de enfermagem); e dura, que é a utilização de instrumentos, normas e equipamentos tecnológicos, que foi usada na construção desta tecnologia (SABINO LMM, et al., 2016).

Por se tratar de tecnologias que estarão atuantes no meio digital, podem surgir indagações quanto seus pontos fracos e fortes. A partir disso, vale ressaltar que tanto o vídeo quanto a cartilha, merecem destaque como uma tecnologia leve-dura, por possuir um método de ensino-aprendizagem lúdico que, além de possibilitar um rápido compartilhamento de informação através das redes sociais e aplicativos multiplataforma de mensagens, pode ser facilmente disponibilizado para alcançar qualquer pessoa, independente da classe social ou do nível educacional (NASCIMENTO LA, et al., 2014).

Com o cenário atual, onde o pânico toma conta da população e com um volume maior na disseminação de informações, faz-se necessário entender e pesquisar quais fontes são confiáveis. Estudos mostram que as pessoas confiam primeiramente no próprio julgamento das fontes e da mensagem para atestar a veracidade de um conteúdo. Quando isso não se mostra suficiente, buscam-se a veracidade em outras fontes, sejam elas interpessoais ou institucionais. Neste caso, é muito importante contribuir para o combate às notícias falsas, como uma forma de acalmar a população. Por isso, as informações contidas nas tecnologias construídas, são de fontes fidedignas e institucionalizadas por órgãos governamentais de ensino e saúde (DELMAZO C e VALENTE JCL, 2018; TANDOC EC, et al., 2017).

Diante desta discussão, refletiu-se que a presença da disciplina "Tecnologias Educacionais em Saúde" na grade curricular dos cursos de Graduação em Enfermagem é de grande valia, principalmente, na formação dos discentes para cenários como o que vivemos atualmente, em que o risco de infecção pela Covid-19 é elevado. E com o devido desempenho dos acadêmicos na conexão com novas tecnologias e combate de patologias em geral, levando conhecimento, faz-se perceber que o uso de informações corretas poderá direcionar a criação de ferramentas que ajudem a população, de forma criativa e que leve tranquilidade, em tempos de pânico. No tocante ao processo de ensino-aprendizagem, consideramos que o uso de ferramentas tecnológicas contribui na construção do conhecimento e no processo de consolidação de educadores em saúde mais reflexivos e com potencial resolutivo (MIRANDA AS, et al., 2020).

Por consequência, devido ao fato de ser uma doença com transmissão simples e rápida, torna-se inviável a realização de ações em saúde comunitárias, o que nos traz a necessidade de utilizar a educação à distância 
como forma inovadora para ações educativas. Sendo assim, tecnologias educacionais virtuais devem ser utilizadas para a disseminação rápida de informações acerca da prevenção de contaminação da doença podendo reduzir o número de indivíduos acometidos. Por fim, a elaboração destas mídias possibilitou aos acadêmicos envolvidos, o crescimento do conhecimento a respeito de uma patologia atual, bem como demonstrou que a Educação em Saúde por meio da Tecnologia Educacional é uma ferramenta eficaz e valiosa em situações alarmantes, como a qual enfrentamos.

\section{REFERÊNCIAS}

1. AGÊNCIA NACIONAL DE VIGILÂNCIA SANITÁRIA (ANVISA). Segurança do paciente em serviços de saúde: limpeza e desinfecção de superfícies. Brasília: Anvisa, 2012.

2. AZEVEDO A, et al. Health education for companions of hospitalized patients. Journal of Nursing UFPE online, 2018; 12(4):1168-1173.

3. BARRETO AEPM, SILVA FRA. Impacto das tecnologias educativas no controle da asma: uma revisão sistemática da literatura. Revista de Medicina UFC, 2015; 55(2): 33-38.

4. BRASIL. Ministério da Saúde. Secretaria de Vigilância em Saúde. Recomendações de proteção aos trabalhadores dos serviços de saúde no atendimento de COVID-19 e outras síndromes gripais. 2020.

5. DELMAZO C, VALENTE JCL. Fake News nas Redes Sociais Online: propagação e reações à desinformação em busca de cliques. Media \& Jornalismo, 2018; 18(32): 155-169.

6. KAMPF G, et al. Persistence of coronaviruses on inanimate surfaces and their inactivation with biocidal agents. The Journal of Hospital Infection, 2020; 104: 246-251.

7. LIU H, et al. Why are pregnant women susceptible to COVID-19? An immunological viewpoint. Journal of Reproductive Immunology, 2020; 139: e103122.

8. MIRANDA SA, et al. Aplicabilidade de atividades lúdicas como parâmetro na recognição do Alzheimer precoce na atenção básica de saúde. Revista Eletrônica Acervo Saúde, 2020; 44: e2250.

9. NASCIMENTO LA, et al. Avaliação de vídeos educativos produzidos no Brasil sobre diarreia infantil: estudo documental. Revista Brasileira de Enfermagem; 2014; 13(3): 311-320.

10. ORGANIZAÇÃO PAN-AMERICANA DA SAÚDE (OPAS). 2020. Princípios norteadores para as atividades de imunização durante a pandemia do virus COVID-19. Disponível em: https://iris.paho.org/bitstream/handle/10665.2/51978/OPASBRACOVID1920029_por.pdf? sequence=1\&isAllowed=y. Acesso em: 17/05/2020.

11. RAMOS TS, ALMEIDA MAPT. A importância do ensino de libras: relevância para profissionais de saúde. Id on line Revista Multidisciplinar e de Psicologia, 2017; 10(33): 116-126.

12. SABINO LMM, et al. Uso de tecnologia leve-dura nas práticas de enfermagem: análise de conceito. Aquichán, 2016; 16(2): 230-239.

13. SALVADOR PTCO, et al. Construção de hipermídia para apoio ao ensino da sistematização da assistência de enfermagem. Revista Gaúcha de Enfermagem, 2019; 40: e20180035.

14. SILVEIRA RSO, et al. Construção de Tecnologia Educativa para Incentivar Puérperas ao leitamento Materno. Mostra Interdisciplinar do curso de Enfermagem, 2016; 2(1): 1-3.

15. SINGHAL T. A Review of Coronavirus Disease-2019 (COVID-19). The Indian Journal of Pediatrics, 2020; 87(4): 281286.

16. STAMM B, et al. A educação em saúde no ambiente hospitalar: relato de experiência sobre prevenção de lesões por pressão. Extensio: Revista Eletrônica de Extensão, 2019; 16(32): 133-140.

17. TANDOC EC, et al. Audiences' acts of authentication in the age of fake news: A conceptual framework. New Media \& Society, 2017; 20(8): 2745-2763.

18. WORLD HEALTH ORGANIZATION (WHO). 2020. WHO Health Emergency Dashboard. Disponível em: https://covid19.who.int/region/amro/country/br. Acesso em: 22/05/2020. 